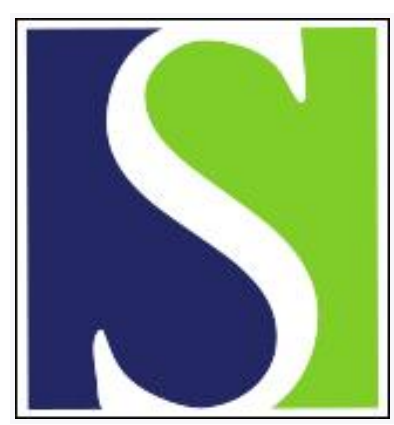

Scand J Work Environ Health 1985;11(3):229-234

https://doi.org/10.5271/sjweh.2230

Issue date: Jun 1985

1984 and occupational health in developing countries.

by Jeyaratnam J

This article in PubMed: www.ncbi.nlm.nih.gov/pubmed/4035326

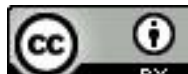

This work is licensed under a Creative Commons Attribution 4.0 International License 


\title{
1984 and occupational health in developing countries
}

\author{
by Jeyarajah Jeyaratnam, MBBS, MSc (Lond), PhD (Lond), MFOM (UK)
}

\begin{abstract}
JEYARATNAM J. 1984 and occupational health in developing countries. Scand $J$ Work Environ Health 11 (1985) 229-234. The developing countries constitute a large and important sector of the world. Their needs and aspirations require serious consideration by the international scientific community. When considering the countries of the developing world, it must be appreciated that they do not constitute a homogeneous entity but are a disparate group with different cultural backgrounds and at varying stages of economic and industrial development. But in spite of such diversity, it is possible to establish at least two issues of common interest to these nations. The first is in relation to the setting of environmental standards in the workplace. In the setting of such standards cultural, political, social, economic, and administrative factors must be taken into consideration. In some situations, for economic reasons, the standards may have to be less stringent than the prevailing standards in the industrialized world. On the other hand, because of administrative and health reasons, they may have to be more stringent. Finally, the issue of scientific research relevant to developing countries is considered in the paper.
\end{abstract}

Key terms: acute pesticide poisoning, environmental standards, health-based limits, permissible levels, pesticides, research, Third World countries.

\begin{abstract}
A knowledge of the past prepares us for the crisis of the present and the challenge of the future.
\end{abstract}

\section{John F Kennedy}

I would like to begin my presentation with a brief account of the problems and aspirations of a certain new nation.

\begin{abstract}
At the time of the Nation's strong declaration of separation, absolving it from the allegiance to the crown, agriculture was the base of the new nation's economy. Industry with the diverse technologies needed to make it flourish had yet to occur. The nearly three million colonials looked forward to economic independence. But with the establishment and early successful growth of the systems of production, there was little awareness of the human injury to accrue from the expansive industrialization about to begin [adapted from Felton (3)].
\end{abstract}

The country referred to in this account is probably the most technologically advanced nation in the world today - the United States of America. I was struck by the similarities between the United States in its early developmental stages and the situation as it exists today among many nations of the developing world. We look to history to provide us with not only hope, and but also direction.

The recognition and the concern of the XXI International Congress on Occupational Health for the health of the working population of the developing world is indeed justified. It is estimated that the de-

\footnotetext{
1 National University of Singapore, Department of Social Medicine and Public Health, Singapore.
}

Reprint requests to: Dr J Jeyaratnam, Department of Social Medicine and Public Health, National University of Singapore, Outram Hill, Singapore 0316, Republic of Singapore. veloping world accounts for approximately $73 \%$ of the world's population, over $70 \%$ of the earth's land mass, and for about $70 \%$ of the world's workforce. Thus the so-called "Third World" is in fact "three quarters of the world," and, furthermore, it is a growth situation. The International Labour Organisation (ILO) estimates that by the end of 1987 some six workers out of ten will live in Asia, one in Western Europe, one in Africa, one in the Soviet Union, and one in the Americas (11). In discussing occupational health in the developing world, we are discussing a problem of some considerable importance. It cannot be ignored.

The term "developing world," which I have been using, is but one of the many synonyms in current use, eg, "nations of the south," "industrializing nations," and "underdeveloped world" are some of the others. To define the developing world, a recent report of the International Bank for Reconstruction and Development (10) categorizes the world by large groupings as follows:

The developing countries: that is, (i) low income countries, with a 1981 gross national product of less than USD 410.00 per person, (ii) the middle income countries with a 1981 gross national product per person of more than USD 410.00 . This group of nations is further divided into oil exporting nations and oil importing nations, (iii) high-income oil exporters, and (iv) least developed countries.

The industrial market economies: these are members of the Organisation for Economic Cooperation and Development (OECD), except for Greece, Portugal, and Turkey, which are included among the middleincome developing nations. 


\section{The East European nonmarket economies.}

Such a grouping of nations is crude and provides a rather simple basis for the identification of common problems. It cannot be overemphasized that an important characteristic of the developing world is that it consists of nations of great diversity. They are culturally disparate, geographically remote from each other, and, besides, are at various stages of economic and industrial development and often governed by different political ideologies and systems. It is important that we recognize these differences, for all too often we are prone to discuss them as a homogeneous group of nations. Such discussions must suffer from a lack of detail and often may appear inaccurate in the context of each nation within the group. The disparate nature of this group of nations is only too evident when one takes a casual look at the predominant occupational pursuits in these nations.

In the face of such disparity, if one were asked to identify a single factor common to these nations, without doubt it would be their urgent need for economic advancement. As would be expected, most of these efforts at economic development would be manifest in the process of industrialization, as well as the modernization of agricultural practices. As such, our discipline of occupational health must be perceptive of the situation in these nations and function within the framework of the economic and social reality as it exists.

In this paper I would like to address two issues: first, that of environmental standards and, second, the problem of research in relation to occupational health.

\section{Environmental standards for developing countries}

The environmental standards or permissible levels of harmful agents in the work environment have been the subject of several authoritative papers and have been adequately defined in ILO and World Health Organization (WHO) documents $(7,12,15)$. In the present discussion I would like to consider the relevance of such environmental standards to the nations of the developing world and the problem of whether we should try to achieve international consensus on environmental standards, eg, are the standards of Sweden appropriate for Sri Lanka? It is pertinent that such questions be asked, as the standards set in the nations of the developing world are to a greater or lesser extent based on the standards of the industrialized nations, particularly those of the United States or the Soviet Union.

In view of this fact it is appropriate to determine, in the first place, if uniformity of standards exists within the industrialized nations. A comparison of the standards set by the United States and the Soviet
Union for a set of 70 compounds shows that only 20 have similar values, whereas 30 differ by a factor of 2 , and 20 compounds differ by a factor of around 50 , the values of the Soviet Union being more stringent (19) - A situation which continues to exist inspite of efforts by international agencies $(12,15)$, individual scientists $(20,21,26)$, international conferences (13), as well as the exchange mission between American and Soviet scientists (18) to achieve some uniformity in standards. Though admittedly, in the last few years WHO, through its expert committee meetings on health-based limits for various toxic substances, has begun to narrow the gap, differences still exist. I raise this issue to spotlight the fact that variations in standards exist even within the nations of the industrialized world. By the same token the differences in standards between the nations of the developing world and the industrialized world should be even greater, but all too often we seem to strive for uniform international standards. At this stage it is relevant for me to consider briefly some of the factors which determine the setting of standards. Basically the concept of environmental standards includes the assumption that a threshold level for a hazard is based on the existence of a "zero effect" level for each substance or factor $(6,8,9)$, though, as might be expected, there is much debate on this subject, particularly with regard to the known carcinogens. Besides these scientific issues there exists certain differences as to what constitutes health. Furthermore both Dinman (2) and WHO (24) have quite appropriately identified the importance of historical, economic, social, cultural, and political considerations which influence the setting of environmental standards and have thereby acknowledged the position that scientific data are not the sole determinant of environmental standards.

For instance Dinman (2) believes that one of the main reasons for the divergence in environmental standards between the United States and the Soviet Union is a difference in the philosophical basis for science. He believes that western science, being influenced by Descartes, perceives a dualism between the body and mind which allows it to dissociate science from political dogma, whereas he believes that science in the Soviet Union, being influenced by Pavlov, emphasizes the unity of body and mind which allows the Soviet scientist to see no duality between science and political dogma. I raise this issue to demonstrate the importance of some of the more abstruse factors which influence the decision making in seemingly simple matters of science.

But unfortunately the factors outside science and health are not given adequate recognition by the scientists of the developing world, particularly when decision makers are being advised about the setting of environmental standards. We must recognize the desperate need and the efforts being made by these nations for economic growth. For instance, as an in- 
dicator of the extent of the socioeconomic problems of these nations, it is estimated that by 1987 one out every four persons in the world will be living in poverty. Unemployment is a major problem; it is estimated (11) that some 600 million extra jobs will have to be created between 1980-1987 in order to give each member of the workforce in these nations an income adequate to meet his own basic needs and that of his family. The very social fabric of these nations is threatened - material growth is imperative. To achieve this growth, these nations, like America during the early stages of development, have chosen to undertake industrialization as the path to economic emancipation. As such, one would agree that the environmental standards proposed by scientists must reflect the aspirations of these nations. These standards must not in any way stifle industrial progress to the extent that they cause more harm than the good that they were intended to do. Gilson (5), recognizing this problem, states "One may reach agreement on the biological aspects of the dose-response relationship of a toxic substance, but the final threshold limit values are not based solely on biological evidence but also on social, economic and other factors in a particular country [p 242]." These are sentiments supported and substantiated by Lawther (17), who makes a plea for what he considers to be a vital need for "a rigorous assessment of the criteria, the guidelines, the standards, now being imposed on many countries that are becoming industrialised, to an extent which is producing economic distress out of all proportion to the good they purport to do." $\mathrm{He}$ goes on to state

I have seen standards adopted by which a factory could not be built if air pollution were to exceed an annual average of $0.01 \mathrm{ppm}$ of sulphur dioxide $-\mathrm{a}$ meaningless figure clinically, but it has closed factories .... I have seen the diesel vehicle, one of the most economic forms of transport, banned from at least one country because its exhaust contains 3-4 benzpyrene. Diesel smoke can contain polycyclic hydrocarbons but there is no evidence that they are harmful in these concentrations .... In one country I have seen the application of erroneous blood carbon monoxide measurements which led to policemen having gas masks and oxygen cylinders, because nobody looked critically enough at the analytical methods used.

These examples provided by Lawther demonstrate evidence of unnecessary action resulting from a lack of perception of socioeconomic needs in the setting of environmental standards. Further they depict the overenthusiastic and sometimes erroneous use of scientific data resulting in somewhat irrelevant and costly decisions. Pitfalls are frequently encountered, which need to be recognized as such, if they are to be avoided. Therefore I believe scientists in the developing countries must temper scientific decisions with an acute sense of social responsibility. Such action is particularly relevant with today's ease of internation- al travel and excellent global communications network. Scientists, even in the remotest corner of the globe, have relatively ready access to the most recent and sophisticated scientific developments occurring in any part of the world, a process which creates a wide gap between scientific knowledge and factors such as industrial development, economic independence, and administrative ability. This is a gap which scientists must be conscious of, as in many instances it may not be appropriate to impose modern science in a socioeconomic setting which is not ready to receive it.

Science has to be modified to suit the setting. In this context it must be appreciated that the situation faced by the nations of the developing world today is quite different from that which was faced by the nations of the industrialized world during their early developmental period. In these nations, scientific technology developed concurrently with industry, governmental process, administrative skills, and economic growth. The problem of imported scientific knowledge inappropriate to local conditions and stringent environmental controls which could stifle industrial development did not exist, as is often possible today in the nations of the developing world. Equally, the opposite is also true. The technology of the industrialized nations may at times be too sophisticated to be transported to a setting which does not have the administrative and technological machinery to use it without endangering itself. We must be sensitive to these issues and ensure that the scientific and technological activities undertaken are in harmony within the socioeconomic status of each nation.

The question is "How can the developing nations determine environmental standards appropriate to their needs?" It is basically a matter of translating scientific knowledge to fit the sociocultural and economic status of each nation. For example is it possible that scientifically determined environmental standards could in some way be adjusted by an appropriate factor based on an indicator such as the Physical Quality of Life Index (PQLI), an index which reflects the socioeconomic status of each nation? A mere suggestion, but the whole issue of relevant environmental standards suffers from the fact that it has not as yet been given the attention it deserves. I believe it is an issue which could benefit immensely from the collaborative efforts of scientists from both the developing and industrialized world, together with the international agencies, particularly WHO. For too long we have avoided the question because we have no ready answers, and probably it is time for us to address our thoughts to this problem.

\section{Research in relation to occupational health in the developing countries}

The second topic of my paper relates to research. It is estimated (25) that $95 \%$ of all health research 
takes place in the industrialized countries of the world. The developing world accounts for only $5 \%$ of health research. Studies (22) have shown that Asia produced $2.9 \%$ of the total mainstream scientific literature in the world, the Middle East and North Africa $1.4 \%$, Latin America $1.0 \%$, and Africa $0.4 \%$ (a total of $5.7 \%$ ). It is a small component of the total, but, even more importantly, it is a situation which is unlikely to change in the near future. The question that should be asked is whether the fractional amount of research that is being undertaken is of maximal benefit to these nations.

Lambo (16) celebrating the 25th anniversary of WHO's Advisory Committee on Medical Research (ACMR) states that "Medical research without social relevance is of little or no benefit to mankind, nor can medical science be detached from human affairs in general and especially from social and economic influences [p 2]." This is a position which is of some relevance to the developing world, particularly when one considers the extremely modest sums of money available for research. But $I$ believe this concept is not given adequate recognition, and I shall attempt to substantiate my position by using the example of research on pesticides. I take the position that, with regard to pesticides, the extent of each hazard as it prevails in the developing world and the consequent impact on national health priorities are vastly different from that of the industrialized world. Let me expand on this issue.

In the industrialized countries accurate statistics of events of poisoning due to pesticides are readily available. In the United Kingdom in 1979 there were no fatalities attributable to pesticides among farming and forestry workers. In the United States 34 deaths of acute pesticide poisoning were recorded among pesticide workers in 1977 (1). These figures are indicative of the fact that acute pesticide poisoning is a rare event; hence such poisoning is not considered to be a problem in the nations of the industrialized world. The question that arises is whether the same is true for the nations of the developing world. In attempting to answer this question the first stumbling block encountered is the relative paucity of data on the subject. It is this lack of data which stimulated WHO in 1972 to develop a mathematical model to estimate the extent of acute pesticide poisoning in the world. On the basis of this model WHO (23) estimated that about 500000 cases of acute pesticide poisoning occur annually, resulting in over 9000 deaths. Furthermore, it was also estimated that only about $1 \%$ of these deaths occurred in the countries of the industrialized world. Such estimates, together with the data from the industrialized world, suggest that the type of problems resulting from pesticide usage is different in the two situations.

The possibility that the estimate of large numbers of cases of excess acute pesticide poisoning in the developing world merely reflects an excessive usage of pesticides is not borne out by available data. It is estimated that the developing world accounts for only $20 \%$ of the world's agrochemical sales (4), which means that the industrialized world, using $80 \%$ of the world's agrochemicals, suffers only $1 \%$ of all deaths due to acute pesticide poisoning. I believe it is vital that one appreciates this difference in order to formulate any meaningful and relevant research or control program for the problems associated with pesticide use in the developing world.

Recent studies in Sri Lanka confirm and highlight this issue of acute pesticide poisoning. It was shown (14) that Sri Lanka, with a population of around 14.5 million, has approximately 13000 patients admitted each year to government hospitals for treatment of acute pesticide poisoning resulting in approximately 1000 deaths annually. To put these figures in the correct perspective, it is relevant to note that for the same year, while approximately 1000 deaths were recorded as being due to pesticide poisoning, only a total of 646 deaths were recorded as being due to poliomyelitis, diphtheria, tetanus and whooping cough, while not a single death occurred due to malaria. Surely, acute pesticide poisoning must be considered a health problem of high priority in Sri Lanka. But unfortunately it has not yet gained the attention it deserves, a situation which I believe is not peculiar to Sri Lanka but must equally beset many other nations of the developing world. To some extent the scientists in these countries must bear responsibility for this state of affairs, for all too often they tend to concentrate on research studies which are more appropriate and relevant to that of the industrialized world. There are many extenuating reasons for this. Most of the research studies and publications on the health hazards of pesticides concentrate on those aspects relevant to the industrialized world, and it is convenient and fashionable for the scientists of the developing world to follow the mainstream of scientific thinking as set by the industrialized world. Furthermore, a large number of scientists in the developing world, having had their training in the industrialized nations, is more familiar with the scientific technologies of those countries and, on their return home, tend to pursue research programs according to their training, however irrelevant it may be to national needs. On the other hand, the industrialized world, having contained the problem of acute pesticide poisoning, is quite appropriately concerned with the study of the long-term effects of prolonged exposure to low dosages of pesticides. Equally, and again appropriately, they are also concerned with the problem of environmental pollution from pesticides. These are of paramount importance to the industrialized world. But the tragedy is in the application of this type of concern about pesticides to the countries of the developing world, for it would indeed reflect a clear lack of priorities for countries of the developing world to address their research endeavors on pesti- 
cides to their hypothetical mutagenic, teratogenic, or carcinogenic potential. Equally, it would be inappropriate for these countries to concern themselves unduly with the potential problems of the thinning of eggshells of predator birds due to environmental pollution by pesticides. But all too often researchers, the media, and the environmental lobbies of the Third World are more concerned about these problems because they happen to be fashionable issues in the industrialized world. They forget about the fact that $99 \%$ of the deaths due to acute pesticide poisoning occurred in the developing world and that each day large numbers of people are dying of acute pesticide poisoning. The fact that this problem should be our main concern has been validated by a survey of the literature on pesticides. The Index Medicus for 1982 and 1983 had 180 and 224 publications on pesticides for the respective years, of which only two papers were on acute pesticide poisoning for each of these years. The majority of the papers were on pesticide residues, metabolism, pharmacokinetics, mutagenesis, and carcinogenesis, among others.

Another important reason as to why acute pesticide poisoning has not been afforded the recognition it deserves by health authorities is the lack of scientific evidence in most developing nations as to the extent of the problem. WHO's estimate of over 9000 deaths for the world could be considered an underestimate if global estimates are based on the Sri Lankan study. On this basis one would expect approximately 2.9 million cases of acute pesticide poisoning to occur annually in the developing world, resulting in around 220000 deaths. A health problem of some magnitude remains unrecognized due to a lack of objective evidence. The responsibility lies mainly with the scientists, who need to establish the nature and extent of the health hazards arising from pesticide usage, as without this information the decision makers in the health field cannot be faulted if the issue of pesticide poisoning continues to occupy a low-priority position.

In preparation for this paper I undertook a 10-year literature search for publications on occupational health in developing countries, and it revealed that less than $2 \%$ of the publications were on acute pesticide poisoning. A wide gap seems to exist between current research activities and priority health issues. The responsibility is clearly ours, we must increase our consciousness of national needs and use it as our reference point and adapt the scientific technologies of the industrialized world to achieve this end. A recent article by Wad (22), entitled "Science, Technology and Industrialisation in Africa" states

Science and technology which lead to productive growth must have an orientation and character which is intimately related to the structure of society as a whole and in particular to the way the economy works. To this extent it must be realised that the nations of the developing world are not just replications of the nations of the industrialised world, but only poorer and slower in their developmental process. What is needed is not a mere translocation of science and technology from the industrialised world but rather appropriate utilisation of modern technologies to identify and rectify developmental problems as they exist in these nations.

In summary, I have in this presentation indicated that the developing world is large, and the sheer size of it alone provides us with reason enough for it to merit serious consideration. Furthermore, I have examined two issues related to occupational health in developing countries. These issues have been considered in the context of the interrelationship of occupational health in the developing world and the industrialized nations, a relationship which provides for much mutual benefit only if scientists are willing to consider seriously the socioeconomic and cultural climate in which they function.

\section{Acknowledgments}

I would like to thank Professor $\mathbf{P}$ Wai-On of Singapore and Dr MA El Batawi and Dr C Xintaras of WHO for their constructive criticism and help in the preparation of my address. I have also received information and help from Dr B Reverente of the Philippines, Professor Kyu Sang Cho of the Republic of Korea, Drs WH Phoon and D Lim of Singapore and Dr WI Glass of New Zealand, and to them I am thankful. The typing was undertaken with consummate expertise and forebearance by Ms L Poh Choo, and to her I am thankful. My presentation was made a reality because of the invitation extended to me by Professor S Hernberg, Vice-President, Permanent Commission and International Association on Occupational Health, and the Organising Committee of the XXI International Congress on Occupational Health, to them my sincere thanks.

\section{References}

1. Barrons KC. Pesticide poisoning. Farm Chem October (1980) 54-55.

2. Dinman BD. Development of workplace environment standards in foreign countries. J Occup Med 18 (1976): 6, 409-417.

3. Felton JF. 200 years of occupational medicine in the US. J Occup Med 18 (1976): 12, 809-817.

4. Gilson JC. Comment in the discussion of the paper "A Social Anthropological Approach to Health Problems in Developing Countries by G Mars. In: Health and industrial growth: Ciba Foundation symposium. Elsevier, Amsterdam 1975, p 242.

5. Hatch TF. Thresholds: Do they exist? Arch Environ Health 22 (1971) 687-689.

6. Hatch TF. The role of permissible limits for hazardous airborne substances in the working environment in the prevention of occupational disease. Bull WHO 47 (1972) 151-159.

7. Hatch TF. Permissible levels of exposure to hazardous agents in industry. J Occup Med 14 (1972) 134-137.

8. Hatch TF. Criteria for hazardous exposure limits. Arch Environ Health 27 (1973) 231-235. 
9. International Bank for Reconstruction and Development. World development report 1983. Oxford University Press, Oxford 1983, pp 148-149.

10. International Group of National Associations of Manufacturers of Agrochemical Products. The manufacture and formulation of pesticides in developing countries. Brussels 1983. (Technical monograph no 9).

11. International Labour Organisation. Medium-term plan 1982-1987. Geneva 1980. (Supplement to the report of the Director-General: Documents of the 212th (February-March 1980) session of the governing body. International Labour Conference 66th session).

12. International Labour Organisation and World Health Organization, Committee on Occupational Health. Permissible levels of toxic substance in the working environment. International Labour Office, Geneva 1970.

13. International Union of Pure and Applied Chemistry. Proceedings of international symposium on MAC's of toxic substances in industry, Prague, 1959. Butterworths, London 1961.

14. Jeyaratnam J, De Alwis Seneviratne RS, Copplestone JF. Survey of pesticide poisoning in Sri Lanka. Bull WHO 60 (1982): 4, 615-619.

15. Joint ILO/WHO Committee on Occupational Health. Permissible levels of occupational exposure to airborne toxic substances: Sixth report of the Joint ILO/WHO Committee on Occupational Health. World Health Organization, Geneva 1969. (WHO technical report series no 415).

16. Lambo TA. The first major landmark. World Health December (1983) 2

17. Lawther PJ. Comment in the discussion of the paper "A Social Anthropological Approach to Health Prob- lems in Developing Countries"' by G Mars. In: Health and industrial growth: Ciba Foundation symposium. Elsevier, Amsterdam 1975, pp 238-239.

18. Magnuson HJ, Fassett DW, Gerarde HW, Rowe VK, Smythe HF, Stokinger HE. Industrial toxicology in the USSR - Theoretical and applied. Am Ind Hyg Assoc J 25 (1964) 185-197.

19. Roschin AV, Timofevskaja LA. Chemical substances in the work environment: Some comparative aspects of USSR \& US hygienic standards. Ambio 4 (1975) 30-33.

20. Stokinger HE. Paper presented at the 17 th International Congress on Occupational Health, 1972, Buenos Aires.

21. Truhaut R. Paper presented at the Symposium on Air Quality Standards. International Academy of Environmental Safety, Paris 1972.

22. Wad A. Science technology and industrialisation in Africa. Third World Q 6 (1984): 2, 327-350.

23. World Health Organization. Safe use of pesticides. Geneva 1973. (WHO technical report series no 513).

24. World Health Organization. Methods used in establishing permissible levels in occupational exposure to harmful agents. Geneva 1977. (WHO technical report series no 601).

25. World Health Organization. Sixth report on the world health situation: Part one, Global analysis. Geneva 1980.

26. Zielhuis RL. Permissible limits for occupational exposure to toxic agents: A discussion on differences in approach between US and USSR. Int Arch Arbeitsmed 33 (1974) 1-13. 